\title{
O EMPRESARIAMENTO DA EDUCAÇÃO DE NOVO TIPO E SUAS DIMENSÕES
}

\author{
VÂNia Cardoso da Motta ${ }^{1}$ \\ Maria Carolina Pires de Andrade ${ }^{2}$
}

\begin{abstract}
RESUMO: O artigo apresenta o conceito de empresariamento da educação de novo tipo, calcado na teoria do valor-trabalho de Marx e nas concepções de Estado ampliado, aparelhos privados de hegemonia e intelectual orgânico em Gramsci. Destacamos suas dimensões centrais: mercantilização, mercadorização e subsunção da educação ao empresariado. Visando à apreensão de aspectos históricos e conjunturais, universais e particulares desse processo, trabalhamos com os conceitos de capitalismo dependente, de Florestan Fernandes, e empresariamento de novo tipo, da historiadora Virgínia Fontes. Trata-se de um esforço teórico-analítico de reunir elementos estruturais e superestruturais a fim de contribuir para pesquisas que se debrucem sobre a progressiva força política do empresariado na educação brasileira.
\end{abstract}

Palavras-chave: Empresariamento da educação de novo tipo. Mercantilização. Mercadorização. Subsunção da educação ao empresariado.

\section{THE EMPRESARIAMENTO OF THE NEW-TYPE EDUCATION AND ITS DIMENSIONS}

\begin{abstract}
The article presents the concept of empresariamento of the new-type education, based on Marx>s labor-value theory, and on the conceptions of the enlarged State - Gramsci's private apparatuses of hegemony and organic intellectual. Its central dimensions are highlighted: mercantilization, commodification, and subsumption of the education to the empresariado. Aiming to apprehend historical and conjunctural, universal and particular aspects of this process, we work with Florestan Fernandes' concept of dependent capitalism, as well as with historian Virgínia Fontes' concept of new-type empresariamento. It is a theoretical-analytical effort to bring together structural and superstructural elements in order to contribute to studies focusing on the progressive political strength of the empresariado community in Brazilian education
\end{abstract}

Keywords: Empresariamento of new type education. Commodification. Merchandising. Subsumption of education to empresariado.

\footnotetext{
*Este artigo é parte de pesquisa de mestrado de Maria Carolina Pires Andrade, intitulada "A Base Nacional Comum Curricular como Mecanismo de Reprodução Ampliada do Capital no Âmbito da Educação" e orientada por Vânia Cardoso da Motta no Programa de Pós-graduação em Educação da Faculdade de Educação da Universidade Federal do Rio de Janeiro. O projeto foi subsidiado pela Capes no formato bolsista.

1.Universidade Federal do Rio de Janeiro - Faculdade de Educação - Programa de Pós-graduação em Educação - Rio de Janeiro (RJ), Brasil. E-mail: vaniacmotta@gmail.com

2.Universidade Federal do Rio de Janeiro - Faculdade de Educação - Programa de Pós-graduação em Educação - Rio de Janeiro (RJ), Brasil. E-mail: carolina.andradep@gmail.com
} 


\title{
EL EMPRESARIAMENTO DE LA EDUCACIÓN DE NUEVO TIPO Y SUS DIMENSIONES
}

\begin{abstract}
RESUMEN: El artículo presenta el concepto de empresariamento de la educación de nuevo tipo, basado en la teoría del valor-trabajo de Marx y en las concepciones de Estado ampliado, aparatos privados de hegemonía e intelectual orgánico en Gramsci. Enfatizamos sus dimensiones centrales: la mercantilización, la mercadorização y la subsunción de la educación al empresariado. Con el objetivo de comprender los aspectos históricos y coyunturales, universales y particulares de este proceso, trabajamos con los conceptos de capitalismo dependiente, de Florestan Fernandes, y de empresariamento de nuevo tipo, de la historiadora Virgínia Fontes. Es un esfuerzo teórico-analítico de reunir elementos estructurales y superestructurales para contribuir a las investigaciones que se centren en la fuerza política progresiva de la comunidad empresarial en la educación brasilera.
\end{abstract}

Palabras-clave: Empresariamento de la educación de nuevo tipo. Mercantilización. Mercadorização. Subsunción de la educación al empresariado.

\section{Introdução}

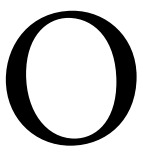

artigo apresenta o conceito de empresariamento da educação de novo tipo, desenvolvido pelo Coletivo de Estudos em Marxismo e Educação (COLEMARX) como suporte analítico às pesquisas que se debruçam sobre a progressiva força política empresarial na educação brasileira nos últimos trinta anos. Compreendemos que a teoria do valor-trabalho de Marx, as concepções de Estado ampliado, aparelhos privados de hegemonia e intelectual orgânico em Gramsci, e os conceitos de capitalismo dependente (FERNANDES, 1981) e empresariamento de novo tipo (FONTES, 2010) são ferramentas teóricas essenciais à apreensão de aspectos históricos e conjunturais, universais e particulares desse processo.

Diversas pesquisas têm abordado indicadores concretos do que definimos como empresariamento da educação de novo tipo, bem como apontado seus efeitos deletérios sobre a educação escolar. ${ }^{1}$ Além disso, vários autores já demonstraram que tanto a capacidade de mobilização política em prol de seus interesses inclusive via apoio de ditaduras e democracias (DINIZ, 2010) - quanto a sistemática disputa por um projeto político-pedagógico hegemônico (BIANCHI, 2001; RODRIGUES, 1998) são características históricas do empresariado brasileiro, cuja atuação transcende a esfera educacional.

Nesse sentido, é necessário ressaltar que a atual força política do empresariado é expressão, segundo Fontes (2010, p. 296), de uma conjuntura mais ampla de "forte concentração capital-imperialista [que] precisa, simultaneamente, contar com a adesão das massas populares nacionais (apassivá-las) [...] e fomentar a extração de sobretrabalho", abarcando as diversas dimensões da vida social, inclusive a educação. Além disso, no Brasil, o empresariado ganha força e novas formas, a partir da Reforma do Aparelho do Estado, sobretudo com a concepção de "público não estatal" e a compreensão de "publicização" como "um sistema de parceria entre Estado e sociedade para seu financiamento e controle” (BRASIL, 1995, p. 13).

No limiar do século XXI, então, o ideário empresarial ganha mais força no cerne da política pública educacional. Nesse contexto, o empresariado se destaca por sua elevada capacidade técnica e dirigente, como pode ser observado no Pacto Global anunciado no Fórum Econômico Mundial em 1999. Tal pacto teve o propósito de formar e consolidar uma rede de vários setores da sociedade (governos, empresários, 
organizações não governamentais, sindicatos e associações acadêmicas) em prol da harmonização do sistema capitalista. Os empresários foram vistos como os agentes principais na adoção de políticas de responsabilidade social e sustentabilidade, a fim de conferir uma dimensão social à acumulação do capital.

Em 2001, frações empresariais locais criaram o Movimento Brasil Competitivo, presidido pelo empresário Jorge Gerdau, com apoio do Banco Mundial e da “'ressuscitada' Agência dos Estados Unidos para o Desenvolvimento Internacional (USAID), copatrocinado pela Merck Sharp \& Dohme, pela Petrobras, e outras grandes empresas" (MOTTA, 2012, p. 125). Em 2006, grandes empresários e banqueiros criaram o Movimento Todos Pela Educação (TPE) e, de imediato, mostraram sua força política no Plano de Metas Compromisso Todos Pela Educação (Decreto n. 6094/2007). Em 2013, organizações como o Instituto Ayrton Senna, a Fundação Roberto Marinho e o TPE criaram o Movimento pela Base Nacional Comum, que construiu e alavancou, em íntima relação com Estado estrito, a Base Nacional Comum Curricular (BNCC), reestruturadora da educação básica brasileira.

Como afirmam Motta e Leher, essas forças firmaram:

um eixo discursivo que irá orientar as ações do capital nos anos seguintes: a educação fundamental foi universalizada, mas carece de qualidade; o Estado e os professores fracassaram na reversão do quadro de repetência, de evasão e de baixo desempenho escolar, então, é legítima a participação ativa da sociedade civil, leia-se, das organizações vinculadas ao capital, na condução dos assuntos educacionais, ainda que em confronto com professores avessos às tais "reformas" (2017, p. 245).

Nesses trinta anos de forte atuação do empresariado, nosso grupo de pesquisa tem evidenciado que a subsunção da educação escolar à forma-mercadoria e à sua lógica, balizada pela necessidade de resolver os problemas da educação brasileira, vem, inversamente, aprofundando-os. A centralidade no resultado imediato e na produtividade da escola tem gerado o aprofundamento do apartheid socioeducacional e mais expropriação dos conteúdos escolares elementares nos campos científico, cultural e artístico, os quais permitem aos jovens entender o funcionamento do mundo das coisas e da sociedade humana. Além disso, tal centralidade tem sido acompanhada do cerceamento do trabalho docente, de desqualificaçãorequalificação da formação docente e da transferência das competências e habilidades necessárias a um mercado de trabalho, predominantemente, de baixo valor tecnológico. Simultaneamente, expandem-se, com velocidade exponencial, as empresas de ensino a distância e de livros e materiais didáticos, bem como os think tanks internacionais, sob incentivo financeiro do Estado.

Diante da complexidade desse processo e da necessidade de freá-lo, buscamos desenvolver uma ferramenta conceitual que contempla seus aspectos contemporâneos, mas também ilumina seus aspectos históricos; que abarca suas especificidades conjunturais e suas relações com os aspectos estruturais da sociedade em que se consolida; que aborda questões imbricadas às relações sociais de produção e à estrutura produtiva, sem esquecer que essas são indissociáveis da manutenção de aspectos político-ideológicos correspondentes.

Assim, o conceito de empresariamento da educação de novo tipo com que trabalhamos combina, dialeticamente, os elementos estruturantes e dinâmicos desse processo, que expressa, sob diferentes mantos, o interesse e a ação das classes dominantes sobre a educação escolar. Hodiernamente, a forma desse processo combina o aprofundamento dos movimentos tendenciais do capital - regidos por sua legalidade particular, condicionada pela dependência - às especificidades econômicas, políticas e sociais do bloco histórico neoliberal erigido no Brasil. Nesse sentido, tal processo ilumina que a tendência do capital de desenvolver 
a dialética do seu devir, subjugando à sua lógica as condições de reprodução social, ratifica características próprias do capitalismo dependente, como a heteronomia cultural, política e social permanente; as formas iníquas de exploração da força de trabalho; os privilégios sociais aberrantes; e a democracia restrita (FERNANDES, 1981). Além disso, no bloco histórico neoliberal, sobressai a hegemonia da concepção econômica de educação, ajustada a tais especificidades: à primazia do mercado, ao novo nexo da dependência e ao padrão de acumulação calcado no trabalho simples, flexível e precarizado.

Cabe ressaltar que o objetivo desse texto não é discutir concretamente as implicações do empresariamento da educação de novo tipo, que podem ser encontradas em vários trabalhos do nosso coletivo. Nas linhas que se seguem, apresentaremos as dimensões centrais desse conceito, elencadas por nós a fim de contemplarmos a complexidade e a historicidade desse processo. São elas a mercantilização (processo pelo qual a educação escolar é subsumida à forma e à lógica da mercadoria), a mercadorização (processo pelo qual a educação escolar é transformada em nicho de mercado) e a subsunção da educação ao empresariado (processo pelo qual o empresariado brasileiro assumiu, em íntima relação com Estado estrito e organismos internacionais, as direções moral e intelectual das educações pública e privada). Ressaltamos que tais dimensões estão profundamente imbricadas e não ocorrem de maneira apartada. A distinção é, pois, apenas teórico-conceitual. Concluímos destacando a importância e a necessidade política de considerar, no âmbito das análises científicas e da luta pela educação pública, a dialética estruturasuperestrutura na especificidade da formação social.

\section{Educação e sua Forma-Mercadoria}

Marx situa a mercadoria como determinação essencial do Modo de Produção Capitalista (MPC), entendendo-a como problema central e estrutural que influencia decisivamente todas as formas de produção e reprodução da vida. Assim, a mercadoria torna-se a forma dominante do metabolismo social e penetra o conjunto das manifestações vitais remodelando, à sua imagem, todas as formas de relação humana.

No MPC a mercadoria se apresenta como valor de uso - destinado à satisfação de necessidades do estômago e da fantasia - e como valor de troca - que constitui a particular forma de manifestação do valor da mercadoria no interior da relação de troca. Nesse sentido, é pressuposto dessa sociedade a produção de valores de uso destinados para a troca; ou seja, valores a serem realizados por outrem. Nesse processo, os trabalhos humanos concretos são equiparados via abstração de suas particularidades e a relação entre eles assume uma forma particular de relação entre coisas, as quais naturalmente possuem valores de magnitude determinada contingencialmente. Essa "objetividade fantasmagórica" da mercadoria interliga e subordina seus produtores, imprime sua estrutura na consciência humana e é fortemente velada pela sua forma acabada, qual seja, a forma-dinheiro (MARX, 2013).

A subsunção formal do trabalho ao capital é um aspecto central do processo de generalização da forma-mercadoria, dado que a força de trabalho aparece para o trabalhador, ela mesma, como uma mercadoria a ser vendida. Nesse âmago, não apenas o dispêndio da força de trabalho continua a ser o determinante do valor oculto pela forma-mercadoria, como também a negação da troca de equivalentes, imprimida pela troca entre capital e trabalho, é fortemente velada pela forma-salário. Oculta-se, assim, que a exploração da força de trabalho é precisamente o lócus de origem de todo valor novo que alimenta a reprodução ampliada do capital.

A subsunção do trabalho ao capital abarca a racionalização da produção e a especialização da força de trabalho, para os quais a adaptação física, cognitiva e psíquica dos trabalhadores é imperiosa. Nesse processo, algumas das qualidades psicológicas do trabalhador são separadas do conjunto de sua personalidade 
e objetivamente colocadas em oposição a ela como coisa - uma mercadoria que pode ser adquirida via treinamento, disciplina, entre outros.

O processo educativo está intimamente vinculado a essa adaptação. Subjugado ao capital, além de fornecer pessoal devidamente treinado à maquinaria, torna-se mais um dos meios de disseminação da ideologia ${ }^{2}$ burguesa, induzindo tanto a perpetuação da exploração do trabalho como mercadoria quanto sua aceitação passiva. Em suma, serve à acumulação capitalista como meio de potencialização da produção de mais-valor e de apassivamento, logrando êxito em fazer com que a classe trabalhadora comungue de sua ideologia.

Nessa ordem, a educação passou a ser elemento constitutivo do valor da força de trabalho, que varia com o valor dos elementos necessários às suas produção e reprodução, as quais, nesse caso, podem ser também de ordem histórica e moral. Sendo a educação elemento indispensável à produção da mercadoria força de trabalho, seus custos "são incluídos no valor total gasto em sua produção" e "variam de acordo com o caráter mais ou menos complexo da força de trabalho" (MARX, 2013, p. 319), já que esse caráter incide também sobre o tempo necessário a tal formação.

Assim, anuvia-se a finalidade social do processo educativo, da mesma maneira que a formamercadoria oculta que a troca é essencialmente uma relação entre atividades humanas. Noutros termos, a subsunção da força de trabalho à forma-mercadoria induz sua reificação, oculta o caráter humano e social de sua produção e abrange também seus processos subjacentes. Nesse meandro, o fato de que a educação é uma forma de reprodução social da existência, construída e operada diária e coletivamente, aparece aos seres humanos de modo turvo, sendo entendida antes como coisa produzida por outrem, de consumo obrigatório por parte daqueles que desejem ocupar um lugar no mundo do trabalho, receber um salário e galgar melhores condições de vida. Nesses moldes, a educação torna-se uma coisa que deve ser consumida pelo trabalhador, mas que somente tem utilidade vinculada à venda de sua força de trabalho.

De acordo com Bruno (2011), os valores de uso e de troca da mercadoria força de trabalho podem assumir uma relação contraditória, a depender da perspectiva de classe. Para a autora, essa mercadoria é valor de uso para o capitalista, já que ele a explora para produzir mais-valor, e interessa-o reduzir ao mínimo possível o seu valor de troca. Sob a ótica do trabalhador, tal mercadoria pode servir como valor de uso, ao utilizá-la na luta organizada contra a exploração.

De modo semelhante, a educação também assumiu valores contraditórios. Sob a ótica burguesa, a educação é útil na medida em que contribui para moldar a força de trabalho em fina sintonia com as exigências do processo de extração de mais-valor. Não ao acaso o conteúdo e a forma da educação são historicamente alvo das ações do capital. Sob a ótica do trabalhador, a educação pode ser valor de uso quando estimula a imaginação inventiva; quando proporciona ferramentas necessárias a leitura, compreensão e questionamento do mundo, bem como à intervenção na realidade. Enquanto lapidadora da força de trabalho, a educação pode até ser compreendida como valor de uso, na medida em que pode facilitar sua venda. Todavia, vale observar que:

1. Esse possível valor de uso, ao contrário daquele existente sob a ótica burguesa, aparece inteiramente dependente da troca e da efetivação do valor de uso da força de trabalho pelo capitalista;

2. O capital busca reduzir esse valor de uso imediato ao trabalhador expropriando, sucessiva e agressivamente, os conhecimentos que potencializam a leitura crítica da realidade, concorrendo ainda para o seu apassivamento;

3. O suposto valor de uso da educação, referente à "facilidade de vender a mercadoria força de trabalho", não apenas vem sendo progressivamente contraposto pela realidade - vide o mercado de trabalho estreito e precarizado -, mas também vem servindo à regulação do preço da força de trabalho, sobretudo a partir da pulverização das ofertas formativas. 
Esse processo de subsunção da educação à forma-mercadoria constitui a mercantilização da educação; um processo tendencial-histórico da sociedade burguesa, mas que assume especificidades no capitalismo dependente. Nele, a educação escolar apresenta particularidades coerentes com a sociedade burguesa erigida via revolução não clássica, na qual são conservados o massivo exército de reserva ${ }^{3} \mathrm{e}$ padrão dual de repartição do excedente econômico sustentado por uma classe trabalhadora duplamente expropriada (FERNANDES, 1981). Corroborando esse autor, a realidade demonstrou que, apesar da luta dos trabalhadores, também no âmbito da educação, a burguesia brasileira nem sequer abraçaria as reformas liberais democráticas. Historicamente, perpetuam-se os privilégios dos setores privatistas e religiosos sobre a educação pública; suas condições estruturais mínimas, a resistência ao investimento público na educação pública e a dualidade educacional estrutural que priva grande parte da classe trabalhadora do acesso à escola e/ou à cultura e aos fundamentos das ciências (SAVIANI, 2013). Nesse sentido, grande parte dos trabalhadores é excluída do acesso ao conhecimento historicamente acumulado, bem como das decisões políticas, de modo que, não ao acaso, o Brasil apresenta atraso secular na universalização do acesso à educação.

Assim, pode-se dizer que a educação escolar mercantilizada no Brasil apresenta, majoritariamente, baixos valores de uso para o trabalhador - pela histórica privação do acesso às bases dos conhecimentos elementares e científicos; pela dificuldade concreta dos trabalhadores de adentrarem o mercado de trabalho formal; e/ou pelas ocupações disponíveis, concentradas nos setores secundário e terciário e em cadeias produtivas de baixo valor tecnológico. No que tange os aspectos estruturais da formação social brasileira, pode-se dizer que, apesar das deficiências do campo educacional, o valor de uso da força de trabalho para os capitalistas manteve-se elevado, uma vez que essa educação é compatível com a maioria das ocupações brasileiras.

Entretanto, as mudanças no mundo do trabalho, a alteração do nexo da dependência e o padrão de acumulação que demanda grande volume de trabalho simples exigiram um trabalhador flexível, com domínio elementar sobre língua portuguesa e matemática, e resiliente - capaz de enfrentar situações de precariedade do mercado de trabalho brasileiro de maneira positiva. Nesse sentido, compreendemos que os elementos da qualificação da força de trabalho brasileira foram cognitivamente ainda mais minimizados e simplificados, porém, socioemocionalmente fortalecidos. Desde a década de 1990, a escolarização que se oferta à classe trabalhadora significa tão somente capacitação da força de trabalho, à medida que há uma elevação considerável do caráter expropriador dos conhecimentos histórico-elementares e uma exacerbação da dimensão instrumental e apassivadora. Vale aqui lembrar que, se o determinante do valor da mercadoria é o tempo despendido na sua produção e se a educação é um elemento de valor da mercadoria força de trabalho, não parece equivocado afirmar que interessa ao capitalista a redução do tempo de trabalho socialmente necessário à capacitação da força de trabalho ${ }^{4}$.

Nesses termos, os trabalhadores não somente são privados das ferramentas necessárias à compreensão crítica da realidade, mas são também estimulados a assumi-la como inapreensível pela razão, imutável e ininteligível, bem como a naturalizá-la e reagir a seus aspectos perversos com corresponsabilidade e ações voluntárias para amenizá-los. Seu valor de troca é ainda mais reduzido: a expansão do acesso à educação precarizada e pulverizada vem contribuindo, de um lado, para "capacitar" o exército de reserva e pressionar os salários para baixo e, de outro, para aligeirar os processos formativos, concorrendo para o rebaixamento do valor da força de trabalho.

A subsunção da educação à forma-mercadoria é, pois, indissociável da sua subsunção à lógica da lucratividade. Nesse sentido, a mercantilização da educação é sincrônica à sua mercadorização; ou seja, à transformação da esfera educacional em nicho de mercado. Nesse, tanto a educação escolar em si, como processo pedagógico, quanto suas ferramentas subjacentes (materiais didáticos, prédios, avaliações, sistemas de ensino e outros) passaram a ser trocados pela forma fenomênica (equivalente universal) do valor. 
Decerto a mercantilização e a mercadorização não são especificidades do bloco histórico neoliberal, dado que tanto as escolas privadas quanto a comercialização de livros e materiais didáticos em escolas públicas são de longa data, assim como a destinação de recursos públicos para os setores privados. Especificamente no Brasil, os setores privatistas, em forte aliança com os educadores católicos, estiveram sempre organizados e presentes nas lutas travadas em torno da educação pública, de modo que seus interesses foram sempre, em alguma escala, atendidos (CUNHA, 2014). De modo geral, a expansão dos nichos de mercado vem sendo acelerada em conjunturas específicas, inclusive como movimento de resposta às crises capitalistas seja como movimento contratendencial à queda na taxa de lucro, seja como meio de aliviar as pressões da sobreacumulação e/ou de proporcionar o escoamento das mercadorias.

Sob a égide do discurso da incapacidade financeira e da ineficiência da administração pública, ocorre não apenas a privatização de tipo clássico, em que há venda de patrimônio público para alguma empresa ou conjunto de investidores, mas também a mercadorização do processo educativo nas redes públicas. Marcadamente no bloco histórico neoliberal, setores privatistas, nacionais e internacionais, expandem aceleradamente seus negócios no mercado educacional: as corporações de capital aberto - a exemplo da Pearson, holding britânica que comercializa sistemas de ensino; da Kroton (agora Cogna), maior corporação do setor educacional brasileiro ${ }^{5}$; e do Grupo Positivo, holding brasileira do ramo gráfico-editorial e informática ${ }^{6}$ - e a exponencial inserção do empresariado na educação pública via parcerias público-privadas, consórcios e administração direta de instituições públicas - são bons exemplos.

\section{Subsunção da Educação ao Empresariado}

É de suma importância destacar que a mercantilização e a mercadorização da educação, no tempo presente, imputam um controle sem precedentes, por parte da classe dominante, sobre o conteúdo e a forma da educação escolar. Nesse sentido, a produção em larga escala de produtos para consumo nas escolas, o gerenciamento das redes públicas por parte de empresas privadas e os vários mecanismos de controle direto e indireto não apenas ampliam a circulação de capital na educação. Mais que isso, deixam sob controle do empresariado, e de sua respectiva concepção de educação, tanto o currículo quanto a organização do trabalho docente, já que, na prática, em vez de aquele servir de suporte a esse, o professor acaba trabalhando o conteúdo previsto nos materiais e cobrado nas avaliações.

O empresariado é apreendido por nós como um seleto grupo de empresários (banqueiros, industriais, agropecuaristas, financistas e respectivos executivos) que, dotado de uma determinada "capacidade técnica e dirigente", assume posição de prestígio e, portanto, de confiança na relação social de produção capitalista. Esse empresariado cumpre a função de corroborar a hegemonia burguesa, tanto no âmbito econômico quanto no político-ideológico, mesmo porque é uma das camadas criadas pela "classe que nasce e desempenha função essencial no plano da estrutura econômica" com vistas a lhe conferir "homogeneidade e consciência da própria função, não apenas no campo econômico, mas também no social e político" (GRAMSCI, 2001, p. 15). Com essa expressão, fundamentada na concepção de intelectual orgânico apresentada em Gramsci (2001), buscamos abarcar a lógica empresarial: sua capacidade técnica - que penetra todas as esferas da relação social por meio de vários mecanismos de controle - e, sobretudo, sua capacidade dirigente, de produção de consenso, tanto para com os aliados, em torno de uma direção comum, quanto dos diferentes tipos de consenso obtidos da classe dominada, esses últimos predominantemente encouraçados pela coerção.

Vale relembrar que, no Pacto Global, o empresariado foi anunciado pelos organismos internacionais como força central para acobertar o antagonismo de classe, construindo uma relação harmônica entre 
mercado, Estado e sociedade civil. Tratou-se de um momento em que a política neoliberal globalizou e aprofundou sobremaneira as expressões da "questão social" , criando uma onda de subversivismo das classes subalternas, a qual obrigou o Estado neoliberal a conferir uma "face mais humana ao capital", sob auspício de uma sociedade harmoniosa (MOTTA, 2012).

No Brasil, esses princípios, ainda associados à ideia do envolvimento dos cidadãos nos assuntos públicos, teve sua expressão na contrarreforma ${ }^{8}$ do Estado, de 1995. Nela, converteram legalmente direitos sociais e universais em "serviços públicos não estatais" e proporcionaram as condições jurídicas para a expansão de organizações sociais empresariais. A regulamentação de OS e OSCIP ${ }^{9}$ criou condições para o exponencial crescimento, particularmente, das organizações sociais empresariais ligadas à educação. Entre 1996 e 2005, o crescimento das organizações da sociedade civil foi de 215,1\%, tendo passado de 107,3 mil para 338,2 mil em todo o Brasil (OJEDA, 2012); em 2016, esse número chegou a 820 mil (LENCIONI, 2018). Em 1996, havia um total de 49.129 empresas no mercado educacional; esse número passou para $61.430 \mathrm{em}$ 2006 e, em 2016, para 101.430 - aumento de quase 50\% em dez anos (IBGE, 2019).

Embora presente em toda a história da educação brasileira, esse empresariado consegue, no bloco histórico neoliberal, inclusive com aparatos legais e financiamento público (LEHER, 2010), penetrar todos os âmbitos da esfera educacional, fazendo-a funcionar de acordo com o ethos empresarial. Ao mesmo tempo que alavanca a produção e a circulação de mercadorias educacionais, determina seus conteúdo e forma de acordo com a concepção econômica da educação ajustada ao bloco histórico neoliberal, como já abordado quanto à mercantilização da educação.

No que concerne a superestrutura, a miríade de organizações sociais empresariais atuando no campo educacional forma uma verdadeira trincheira da luta de classes. Trazendo Gramsci, essa trincheira de aparelhos privados de hegemonia protege sobremaneira o Estado capitalista, ao complexificar a luta de hegemonias travada na sociedade civil - estrutura entrincheirada, complexa e muito "resistente às 'irrupções' catastróficas do elemento econômico imediato (crises, depressões etc.)” (GRAMSCI, 2007, p. 73).

Nesse sentido, pode-se afirmar que o empresariado brasileiro atual, mais organizado e fortalecido politicamente, ratifica que a escolarização é um dos mecanismos de conformação, internalização e sedimentação da forma burguesa de enxergar e compreender o mundo, inclusive sua estrutura de classes; ou seja, é ferramenta de cimentação ideológica de qualquer bloco histórico que se inaugure sob a égide do MPC. É em prol da manutenção desse conformismo social das massas e da construção de uma "vontade do conformismo" - que opere "segundo as exigências do fim a alcançar [...] e que seja útil à linha de desenvolvimento do grupo dirigente" (GRAMSCI, 2007, p. 119) - que o empresariado vem, no campo da educação escolar,

1. Educando e organizando o consenso "espontâneo" das massas - aquele "dado pelas grandes massas da população à orientação impressa pelo grupo fundamental dominante à vida social” (GRAMSCI, 2001, p. 21) - por meio do uso intensivo da mídia com discursos que se confundem com suas reivindicações, como a busca pela qualidade da educação, educação integral, igualdade de oportunidades, empregabilidade, desenvolvimento econômico do país e outras "motivações" genéricas, imprecisas, por vezes contra intuitivas ${ }^{10}$ mas convincentes;

2. Buscando e promovendo o consenso ativo (GRAMSCI, 2007) - aquele construído quando os governados aceitam a condução do aparato estatal e coparticipam da vida desse organismo -, ao conclamar parcelas seletas da classe trabalhadora para debater reformas na educação, a exemplo das Conferências Nacionais de Educação (Conae), para a construção do Plano Nacional da Educação e das consultas públicas realizadas para definir a BNCC; 
3. Buscando e reforçando o consenso passivo das massas - aquele que tem como base fundamental "conseguir convencer [a classe dominada] sobre a inelutabilidade da própria ação" (GRAMSCI, 1999, p. 449); ou seja, a incredulidade na força política da atuação da classe trabalhadora para si e na possibilidade de rompimento com as relações sociais capitalistas, ratificando, em seus discursos e ações, que a educação oferecida sob o comando do empresariado é a melhor, senão a única possível nessa sociedade;

4. Operando mecanismos de coerção direta ou indireta via aparelhagem estatal para assegurar “'legalmente' a disciplina dos grupos que não 'consentem', nem ativa nem passivamente”, ou para reestabelecer a ordem em "momentos de crise no comando e na direção, nos quais desaparece o consenso 'espontâneo"' (GRAMSCI, 2001, p. 21), a exemplo da aprovação, no governo Temer, da Reforma do Ensino Médio, via medida provisória, e da BNCC, mesmo diante de críticas e resistência dos profissionais da educação.

Enfim, nos últimos trinta anos, a atuação do empresariado organizado para dirigir a educação brasileira, em íntima relação com o Estado estrito, ratifica a infindável dupla perspectiva do Estado burguês, correspondente "à natureza dúplice do Centauro maquiavélico, férica e humana, da força e do consenso, da autoridade e da hegemonia, da violência e da civilidade, do momento individual e daquele universal [...], da agitação e da propaganda, da tática e da estratégia" (GRAMSCI, 2007, p. 21) para manter condições favoráveis à acumulação de capital.

\section{Considerações Finais}

Buscamos apresentar, brevemente, os elementos centrais que nos conduziram à formulação do conceito de empresariamento da educação de novo tipo. O empresariamento, no bloco histórico neoliberal, combina o aprofundamento de movimentos tendenciais no âmbito da educação (a mercantilização e a mercadorização) à forma contemporânea do capital, bastante eficiente, de exercer controle em larga escala sobre a educação escolar.

Assim, nesse bloco histórico, exacerbam-se suas faces capacitadoras e apassivadoras. A educação, como mercadoria, tem seu valor de uso e de troca reduzido ao mínimo na perspectiva da classe trabalhadora; tem seu valor de uso elevado na perspectiva burguesa, ao mesmo tempo que essa classe pressiona o valor e o preço da força de trabalho para baixo, pulverizando e acelerando os processos formativos e capacitando o exército de reserva, respectivamente. Esse aprofundamento de aspectos estruturais do MPC está intimamente vinculado ao amplo controle do empresariado na educação. No momento da crise orgânica que se instaurou nos anos 1980, o empresariado assumiu para si as tarefas de, simultaneamente, conformar a classe trabalhadora para formas instáveis de vida e aberrantes de extração de mais-valor e ampliação do mercado educacional, que hoje já movimenta mais de 100 bilhões de reais.

No Brasil, esse processo agrava ainda as especificidades do capitalismo dependente: amplia a restrição do acesso da classe trabalhadora aos conhecimentos mais elaborados que permitem o entendimento do funcionamento do mundo das coisas e da sociedade humana; mantém a dualidade educacional com aspectos de novo tipo (RUMMERT et al., 2013); e aprofunda a massificação educacional, corroborando os mecanismos de exclusão, expropriação e opressão de grande parte dos trabalhadores. Nesse cenário, o empresariado combina farsa e tragédia: apresenta-se como grupo social que gera riqueza, trabalho e renda para a "nação" em meio a seu reverso - um capitalismo perverso, sustentado pela miséria da classe 
trabalhadora -, colocando-se como aquele que elevará moral e culturalmente a massa de trabalhadores, ao passo que expropria dela os conhecimentos elementares e dirige seu processo de apassivamento.

Nosso objetivo primeiro foi discorrer sobre aspectos estruturais e conjunturais que, juntos, aprofundam precarização e expropriação dos processos formativos mais complexos, bem como endossam o que denominamos empresariamento da educação de novo tipo. Em segundo lugar, buscamos ressaltar o referencial teórico-metodológico que permite compreender o fato de que a esfera educacional não se faz exceção ao ponto de vista da totalidade, tampouco da dialética estrutura-superestrutura. Por isso, pensar os problemas atuais da educação brasileira e lutar pela sua (certamente) possível transformação exige estar nas trincheiras da luta de hegemonias travada na sociedade civil, fazendo, porém, frente aos aspectos da estrutura econômica que conformam um padrão de acumulação cuja existência se dá pela exploração e pela expropriação humana, independentemente do tempo histórico.

\section{Contribuição dos Autores}

Problematização: Motta VC, Andrade MCP; Conceitualização: Motta VC, Andrade MCP; Referencial teórico-metodológico: Motta VC, Andrade MCP; Procedimentos metodológicos: Motta VC, Andrade MCP; Análise: Motta VC, Andrade MCP; Redação: Motta VC, Andrade MCP.

\section{Notas}

1. Além do Colemarx, temos, no Brasil, sólidos grupos de pesquisa e pesquisadores que se debruçam sobre a questão do empresariado na educação, tais como: Gaudêncio Frigotto (Uerj), Lúcia Neves (UFF), André Martins (UFJF), Luiz Carlos Freitas (Unicamp), Theresa Adrião (Unicamp/Unemat) e Vera Peroni (USP), entre outros. Na perspectiva da teoria do valor, citamos Glenn Rikowski, Lúcia Bruno e José Rodrigues.

2. Ideologia aqui entendida como conjunto de ideias pelo qual a classe dominante expressa, no âmbito ideal, a relação concreta de dominação com elementos de inversão, ocultamento, justificação, falseamento, naturalização, apresentação do interesse particular como universal e outros. Nesses moldes, essas ideias cumprem a função de cimento social dessas relações, induzindo sua aceitação passiva.

3. Referimo-nos ao conceito de Exército Industrial de Reserva de Marx (2013, p. 716), que abarca a parte da classe trabalhadora que é condenada à ociosidade graças ao trabalho excessivo de outra parte, não sendo inserida no mercado de trabalho. Essa parcela é funcional ao MPC na medida em que força a redução do preço da força de trabalho, ao manter sua oferta em patamares superiores ao demandado pelo Capital.

4. Neste processo, podemos indicar as reformas curriculares que reduzem a carga horária ou eliminam disciplinas não imediatamente úteis ao processo de valorização do valor. Podemos indicar também a defesa à oferta de ensino a distância como complemento curricular ou forma de capacitação da força de trabalho. Nesse último caso, especificamente, observamos uma significativa redução do dispêndio de capital por parte do capitalista, tanto de modo constante quanto variável. O capital constante pode ser bastante reduzido, por exemplo, pela economia das despesas com instalações e infraestrutura; o variável pode ser reduzido pelo fato de, primeiramente, o ensino a distância possibilitar a redução da contratação de professores, uma vez que cada um deles pode atender muito mais alunos, inclusive simultaneamente, Além disso, é fato que a própria economia com instalações possibilita redução das despesas com a contratação de pessoal (funcionários de limpeza, secretários, monitores, entre outros).

5. Atualmente, a Kroton (agora Cogna) e a Gera Venture criaram holdings especificamente dedicadas à educação básica, como a Saber Educacional e a Eleva Educação. A Kroton já atende 34,2 milhões de alunos com seus sistemas de ensino e, de acordo com o CEO, Galindo, aumentará as apostas no ensino básico, já que, no Brasil, existem 30,6 mil escolas particulares e apenas 2,4 mil faculdades, além de o mercado de ensino básico movimentar, anualmente, R\$ 101 bilhões - quase o dobro do Ensino Superior.

6. Essa vem estimulando a configuração de "arranjos de desenvolvimento da educação" junto a um conjunto de municípios e vende para essas redes de ensino seus produtos: Solução Habile Sistema de Avaliação; Solução Gero Gestão Escolar Integrada; Solução Enem Express Preparação Intensiva; Solução Sistema de Ensino Aprende Brasil - entre inúmeros outros (ADRIÃO et al., 2016; DOMINGUES, 2017; MOTTA; ARGOLLO, 2016).

7. Na perspectiva da teoria social crítica, a questão social expressa as configurações assumidas pelo trabalho no decorrer do desenvolvimento capitalista; ou seja, está situada na arena de poder e imprime as disputas entre classes e frações de classes. 
Sob a ótica da classe dominante, então, é uma ameaça à ordem e à coesão social e deve ser permanentemente controlada e administrada. Suas expressões são reveladas por desemprego, precarização do trabalho e pobreza, entre outras mazelas sociais.

8. Contrarreforma para indicar que as "reformas" postas em marcha sob a égide do neoliberalismo destinam-se à supressão ou à redução de direitos e garantias sociais.

9. Em 1998, com a Lei n. 9.637, foram qualificadas as Organizações Sociais (OS), entidades privadas que passaram a absorver atividades de setores públicos. Em 1999, por meio da Lei n. 9.790, foram regulamentadas as Organizações da Sociedade Civil de Interesse Público (OSCIP), com liberdade para atuar na "promoção gratuita da educação, observando-se a forma complementar de participação das organizações de que se trata esta lei” (BRASIL, 1999).

10. Exemplo clássico desses objetivos contraintuitivos é o argumento de que o empresariamento da educação é mais eficiente, em termos de custo, do que a educação oferecida pelo Estado, uma vez que o prestador privado, mesmo via contrato de gestão, aproveita a diferença entre os pagamentos feitos por governos locais e seus gastos para garantir o seu lucro. Nesse sentido, o lucro é, portanto, um custo a mais para o fundo público, e não o contrário.

\section{Referências}

ADRIÃO, T. et al. Grupos empresariais na educação básica pública brasileira: Limites à efetivação do direito à educação. Educação \& Sociedade, Campinas, v. 37, n. 134, p. 113-131, jan.-mar. 2016. https://doi.org/10.1590/ ES0101-73302016157605

BIANCHI, Á. Hegemonia em construção - A trajetória do PNBE. São Paulo: Xama, 2001.

BRASIL. Ministério da Administração Federal e da Reforma do Estado. Plano Diretor da Reforma do Aparelho do Estado. Brasília, DF, 21 set. 1995.

BRASIL. Lei n. 9.790, de 23 de março de 1999. Dispõe sobre a qualificação de pessoas jurídicas de direito privado, sem fins lucrativos, como organizações da sociedade civil de interesse público, institui e disciplina o termo de parceria, e dá outras providências. Diário Oficial da União, Brasília, DF, 24 mar. 1999.

BRUNO, L. Educação e desenvolvimento econômico no Brasil. Revista Brasileira de Educação, Rio de Janeiro, v. 16, n. 48, set.-dez. 2011. https://doi.org/10.1590/S1413-24782011000300002

CUNHA, L. A. Ensino profissional: O grande fracasso da ditadura. Cadernos de Pesquisa, São Paulo, v. 44, n. 154, p. 912-933, out.-dez. 2014. https://doi.org/10.1590/198053142913

DINIZ, E. Empresariado industrial, representação de interesses e ação política: Trajetória histórica e novas configurações. Revista Política \& Sociedade, v. 9, n. 17, p. 101-139, out. 2010. https://doi. org/10.5007/2175-7984.2010v9n17p101

DOMINGUES, A. A inserção do Grupo Positivo de Ensino no sistema educacional público: Educação sob o controle do empresariado. 2017. Tese (Doutorado em Educação) - Programa de Pós-graduação em Educação, Universidade Federal de Santa Catarina, Santa Catarina, 2017.

FERNANDES, F. Sociedade de classes e subdesenvolvimento. Rio de Janeiro: Zahar, 1981.

FONTES, V. O Brasil e o capital imperialismo: Teoria e história. Rio de Janeiro: EPSJV/Editora UFRJ, 2010.

GRAMSCI, A. Cadernos do Cárcere. Rio de Janeiro: Civilização Brasileira, 1999, v. 1.

GRAMSCI, A. Cadernos do Cárcere. Rio de Janeiro: Civilização Brasileira, 2001, v. 2. 
GRAMSCI, A. Cadernos do Cárcere. Rio de Janeiro: Civilização Brasileira, 2007, v. 3.

IBGE [INSTITUTO BRASILEIRO DE GEOGRAFIA E ESTATÍSTICA]. Sistema IBGE de Recuperação Automática. Banco de tabelas estatísticas, [s. d.]. Disponível em: https://sidra.ibge.gov.br/tabela/3543. Acesso em: 15 maio 2019.

IBGE [INSTITUTO BRASILEIRO DE GEOGRAFIA E ESTATÍSTICA]. Estatística do Cadastro Central de Empresas, 2019. Disponível em: https://www.ibge.gov.br/estatisticas/economicas/outras-estatisticaseconomicas/9016-estatisticas-do-cadastro-central-de-empresas.html?=\&t=series-historicas. Acesso em: 15 maio 2019.

LEHER, R. A educação no governo Lula da Silva: A ruptura que não aconteceu. In: Os anos Lula: Contribuições para um balanço crítico (2003-2010). Rio de Janeiro: Garamond, 2010, p. 369-411.

LENCIONI, C. Brasil tem 820 mil organizações da sociedade civil, segundo Ipea. Observatório do $3^{\circ}$ setor. Brasília: Instituto de Pesquisas Econômicas Aplicadas (Ipea), 24 jul. 2018. Disponível em: https:// observatorio3setor.org.br/noticias/brasil-tem-820-mil-organizacoes-da-sociedade-civil-segundo-ipea/. Acesso em: 21 maio 2019.

MARX, K. O Capital: Crítica da economia política. São Paulo: Boitempo, 2013, v. 1.

MOTTA, V. C. Ideologia do capital social: Atribuindo uma face mais humana ao capital. Rio de Janeiro: EdUerj, 2012.

MOTTA, V. C.; ARGOLLO, J. Em curso um Sistema Nacional de Educação nos moldes dos arranjos de desenvolvimento da educação. Revista Contemporânea de Educação, Rio de Janeiro, v. 11, n. 22, p. 281300, ago.-dez. 2016. https://doi.org/10.20500/rce.v11i22.4143

MOTTA, V. C.; LEHER, R. Trabalho docente no contexto do retrocesso do retrocesso. Revista Trabalho, Política e Sociedade, v. 2, n. 3, p. 243-258, jul.-dez. 2017. https://doi.org/10.29404/rtps-v2i3.3580

OJEDA, I. A complexa relação entre Estado e ONGs. Revista Desafios do Desenvolvimento - Ipea, ed. 71, ano 9, 2012. Disponível em: http://www.ipea.gov.br/desafios/index.php?option=com_content\&view=article \&id=2727: catid=28\&Itemid=23. Acesso em: 15 maio 2019.

RODRIGUES, J. O moderno príncipe industrial: O pensamento pedagógico da Confederação Nacional da Indústria. Campinas: Autores Associados, 1998.

RUMMERT, S. et al. Educação da classe trabalhadora brasileira: Expressão do desenvolvimento desigual e combinado. Revista Brasileira de Educação, Rio de Janeiro, v. 18, n. 54, p. 717-738, jul.-set. 2013. https:// doi.org/10.1590/S1413-24782013000300011

SAVIANI, D. Vicissitudes e perspectivas do direito à educação no Brasil: Abordagem histórica e situação atual. Educação \& Sociedade, Campinas, v. 34, n. 124, p. 743-760, jul.-set. 2013. https://doi.org/10.1590/ S0101-73302013000300006 


\section{Sobre os Autores}

VÂnia Cardoso da Motta é doutora em Serviço Social pela Universidade Federal do Rio de Janeiro (UFRJ). Professora Adjunta da Faculdade de Educação e do Programa de Pós-graduação em Educação da UFRJ. Integrante do grupo de pesquisa "Coletivo de Estudos em Marxismo e Educação" (COLEMARX), da Faculdade de Educação da UFRJ.

Maria Carolina Pires de Andrade é Mestranda do Programa de Pós-graduação em Educação da Universidade Federal do Rio de Janeiro (UFRJ). Integrante do grupo de pesquisa "Coletivo de Estudos em Marxismo e Educação" (COLEMARX), da Faculdade de Educação da UFRJ. Bolsista Capes.

Recebido: 23 maio 2019 Aceito 17 jun. 2020 